\title{
Static Analysis of Composite Semi - Elliptical Leaf Spring
}

\author{
D. Helmen Devaraj ${ }^{1}$, M. Venkatesan ${ }^{2}$ \\ ${ }^{I}$ M.E - Engineering Design, Department of Mechanical Engineering, Sona College of Technology, Salem-5, India. \\ ${ }^{2}$ Assistant Professor, Department of Mechanical Engineering, Sona College of Technology, Salem-5, India.
}

\begin{abstract}
:
This project describes design and experimental analysis of composite leaf spring made of glass fiber reinforced polymer. The objective is to compare the load carrying capacity, stiffness and weight savings of composite leaf spring with that of steel leaf spring. The design constraints are stresses and deflections. The dimensions of an existing conventional steel leaf spring of a light commercial vehicle are taken. Same dimensions of conventional leaf spring are used to fabricate a composite multi leaf spring using E- Glass/Epoxy unidirectional laminates. Static analysis of 2-D model of conventional leaf spring is also performed using ANSYS 10 and compared with experimental results. Finite element analysis with full load on 3-D model of composite multi leaf spring is done using ANSYS 10 and the analytical results are compared with experimental results. Compared to steel spring, the composite leaf spring is found to have $67.35 \%$ lesser stress, $64.95 \%$ higher stiffness and $126.98 \%$ higher natural frequency than that of existing steel leaf spring. A weight reduction of $76.4 \%$ is achieved by using optimized composite leaf spring.
\end{abstract}

Keywords - Composite materials, design constrains, leaf spring, material property, and static analysis.

\section{INTRODUCTION:}

In order to conserve natural resources and economize energy, weight reduction has been the main focus of automobile manufacturers in the present scenario. Weight reduction can be achieved primarily by the introduction of better material, design optimization and better manufacturing processes. The suspension leaf spring is one of the potential items for weight reduction in automobiles as it accounts for $10 \%-20 \%$ of the unstrung weight. This achieves the vehicle with more fuel efficiency and improved riding qualities. The introduction of composite materials was made it possible to reduce the weight of leaf spring without any reduction on load carrying capacity and stiffness.

Since, the composite materials have more elastic strain energy storage capacity and high strength to weight ratio as compared with those of steel, multi-leaf steel springs are being replaced by mono-leaf composite springs. The composite material offer opportunities for substantial weight saving but not always are cost-effective over their steel counter parts.

The leaf spring should absorb the vertical vibrations and impacts due to road irregularities by means of variations in the spring deflection so that the potential Energy is stored in spring as strain energy and then released slowly. So, increasing the energy storage capability of a leaf spring ensures a more compliant suspension system. According to the studies made a material with maximum strength and minimum modulus of elasticity in the longitudinal direction is the most suitable material for a leaf spring. Fortunately, composites have these characteristics.

Fatigue failure is the predominant mode of inservice failure of many automobile components. This is due to the fact that the automobile components are subjected to variety of fatigue loads like shocks caused due to road irregularities traced by the road wheels, the sudden loads due to the wheel traveling over the bumps etc. The leaf springs are more affected due to fatigue loads, as they are apart of the unstrung mass of the automobile.

The fatigue behavior of Glass Fiber Reinforced Plastic (GFRP) epoxy composite materials has been studied in the past. Theoretical equation for predicting fatigue life is formulated using fatigue modulus and its degrading rate. This relation is simplified by strain failure criterion for practical application. A prediction method for the fatigue strength of composite structures at an arbitrary combination of frequency, stress ratio and temperature has been presented. These studies are limited to mono-leaf springs only.

In the present work, a seven-leaf steel spring used in passenger cars is replaced with a composite multi leaf spring made of glass/epoxy composites. The dimensions and the number of leaves for both steel leaf spring and composite leaf springs are considered to be the same. The primary objective is to compare their load carrying capacity, stiffness and weight savings of composite leaf spring. Finally, fatigue life of steel and composite leaf spring is also predicted using life data.

\section{LITERATURE REVIEW:}

2.1 Ballinger C.A. - Getting Composites into Construction, Reinforced Plastics, 1995.

Composite leaf spring in the early 60 failed to yield the production facility because of inconsistent fatigue performance and absence of strong need for mass reduction. Researches in the area of automobile components have been receiving considerable attention now. Particularly the automobile manufacturers and parts makers have been 
attempting to reduce the weight of the vehicles in recent years. Emphasis of vehicles weight reduction in 1978 justified taking a new look at composite springs. Studies are made to demonstrate viability and potential of FRP in automotive structural application.

The development of a lit flex suspension leaf spring is first achieved. Based on consideration of chipping resistance base part resistance and fatigue resistance, a carbon glass fiber hybrid laminated spring is constructed. A general discussion on analysis and design of constant width, variable thickness, and composite leaf spring is presented. The fundamental characteristics of the double tapered FRP beam are evaluated for leaf spring application.

Recent developments have been achieved in the field of materials improvement and quality assured for composite leaf springs based on microstructure mechanism. All these literature report that the cost of composite; leaf spring is higher than that of steel leaf spring. Hence an attempt has been made to fabricate the composite leaf spring with the same cost as that of steel leaf spring.

2.2 Miravete.A, Castejon. L, Bielsa.J, Bernal.E - Analysis and Prediction of large composite Structures, 1990.

Material properties and design of composite structures are reported in many literatures. Very little information is available in connection with finite element analysis of leaf spring in the literature, than too in 2D analysis of leaf spring. At the same time, the literature available regarding experimental stress analysis more.

The experimental procedures are described in national and international standards. Recent emphasis on mass reduction and developments in materials synthesis and processing technology has led to proven production worthy vehicle equipment..

\section{SPECIFICATION OF THE PROBLEM:}

The objective of the present work is to design, analyses, Glass Fiber/Epoxy complete composite leaf spring

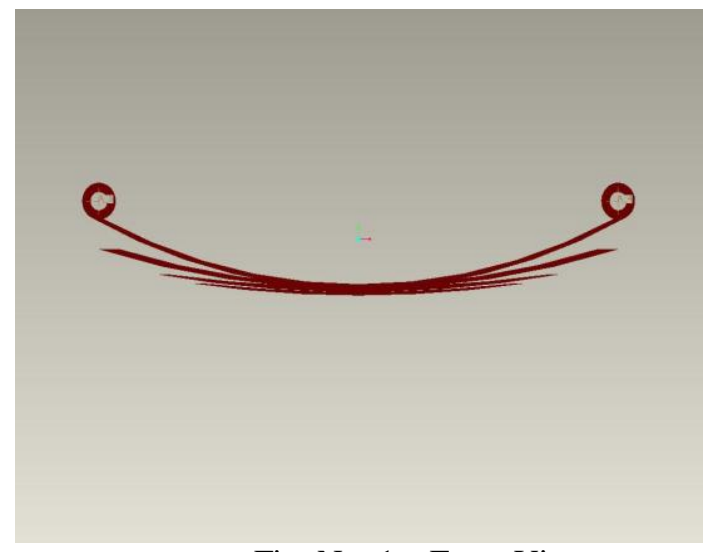

Fig. No: 1 - Front View. with out end joints and composite leaf spring using bonded end joints using hand-lay up technique. This is an alternative, efficient and economical method over wet filament-winding technique.

\section{LEAF SPRINGS:}

Leaf springs also known as flat spring are made out of flat plates. Leaf springs are designed two ways: multi-leaf and mono-leaf. The leaf springs may carry loads, brake torque, driving torque, etc... In addition to shocks.

The multi-leaf spring is made of several steel plates of different lengths stacked together. During normal operation, the spring compresses to absorb road shock. The leaf springs bend and slide on each other allowing suspension movement.

\subsection{Construction of Leaf Spring:}

The leaves are usually given an initial curvature or cambered so that they will tend to straighten under the load. The leaves are held together by means of band shrunk around them at the centre or by a bolt passing through center. Since, the band exerts stiffening and strengthening effect, therefore effective length of the spring for bending will be overall length of the spring minus width of the band.

In case of a center bolt, two-third distance between centers of U-bolt should be subtracted from the overall length of the spring in order to find effective length. The spring is clamped to the axle housing by means of U-bolts. The longest leaf known as main leaf or master leaf has its ends formed in the Shape of an eye through which the bolts are passed to secure the spring to its supports.

The other leaves of the spring are known as graduated leaves. In order to prevent digging in the adjacent leaves, the ends of the graduated leaves are trimmed in various forms. Rebound clips are located at intermediate positions in the length of the spring, so that the graduated leaves also share the stress induced in the full length leaves when the spring rebounds.

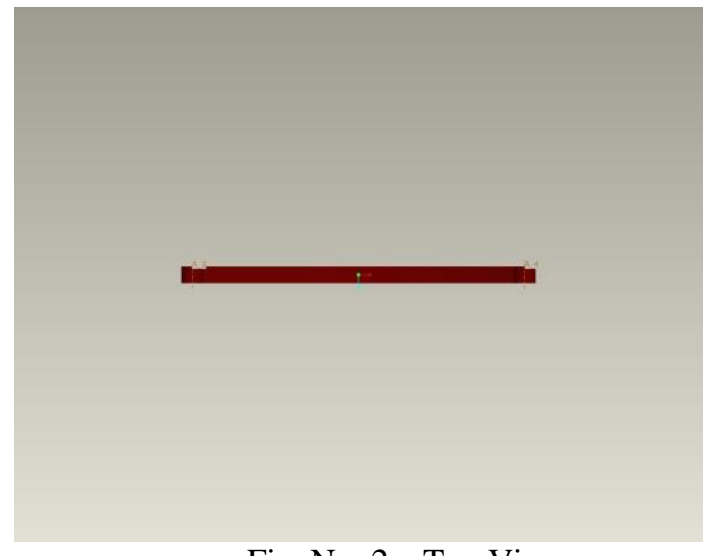

Fig. No: 2 - Top View. 


\subsection{Materials for Leaf Springs:}

The material used for leaf springs is usually a plain carbon steel having 0.90 to $1.0 \%$ carbon. The leaves are heat treated after the forming process. The heat treatment of spring steel products greater strength and therefore greater load capacity, greater range of deflection and better fatigue properties.

For automobiles: $50 \mathrm{Cr} 1,50 \mathrm{Cr} 1 \mathrm{~V} \mathrm{23}$, and 55 Si 2 Mn 90 all used in hardened and tempered state.

For rail road springs: C 55 (water - hardened), C 75 (oil-hardened), $40 \mathrm{Si} 2 \mathrm{Mn} 90$ (water-hardened) and 55 Si 2 M N90 (oil-hardened).

\section{COMPOSITE MATERIAL:}

\subsection{Characteristics:}

A composite material is defined as a material composed of two or more constituents combined on a macroscopic scale by mechanical and chemical bonds.

Typical composite materials are composed of inclusions suspended in a matrix. The constituents retain their identities in the composite. Normally the components can be physically identified and there is an interface between them.

Many composite materials offer a combination of strength and modulus that are either comparable to or better than any traditional metallic materials. Because of their low specific gravities, the strength weight-ratio and modulus weight-ratios of these composite materials are markedly superior to those of metallic materials.

The fatigue strength weight ratios as well as fatigue damage tolerances of many composite laminates excellent. For these reasons, fiber composite have emerged as a major class of structural material and are either used or being considered as substitutions for metal in many weightcritical components in aerospace, automotive and other industries.

Another unique characteristic of many fiber reinforced composites is their high internal damping. This leads to better vibration energy absorption within the material and results in reduced transmission of noise land vibration to neighboring structures.

High damping capacity of composite materials can be beneficial in many automotive applications in which noise, vibration, and hardness is a critical issue for passenger comfort.

Among the other environmental factors that may cause degradation in the mechanical properties of some polymeric matrix composites are elevated temperatures, corrosive fluids, and ultraviolet rays.
In many metal matrix composites, oxidation of the matrix well as adverse chemical reaction between fibers and matrix are of great concern at high temperature applications.

\subsection{Applications:}

Commercial and industrial applications of composite $s$ are so varied that it is impossible to list them all. The major structural application areas, which include aircraft, space, automotive, sporting goods, and marine engineering. A potential for weight saving with composites exists in many engineering field. The first major structural application of composite is the corvette rear leaf spring in 1981. A unileaf E-glass - reinforced epoxy has been used to replace a ten-leaf steel spring with nearly an $80 \%$ weight savings.

Other structural chassis components, such as drive shafts and road wheels, have been successfully tested in the laboratories and are currently being developed for future cars and vans.

The metal matrix composites containing either continuous or discontinuous fiber reinforcements, the latter being in the form of whiskers that are approximately 0.1 $0.5 \mu \mathrm{m}$ in diameter and have a length to diameter ratio up to 200.

Particulate-reinforced metal matrix composites containing either particles or platelet that ranges in size from 0.5 to $100 \mu \mathrm{m}$. Dispersion-strengthened metal matrix composites containing particles that are less than $0.1 \mu \mathrm{m}$ in diameter. And metal matrix composites are such as directionally solidified eutectic alloys.

\subsection{Benefits:}

i. Weight reduction,

ii. High strength,

iii. Corrosiveness,

iv. Low specific gravity.

\section{DESIGN SELECTION:}

The leaf spring behaves like a simply supported beam and the flexural analysis is done considering it as a simply supported beam. The simply supported beam is subjected to both bending stress and transverse shear stress. Flexural rigidity is an important parameter in the leaf spring design and test out to increase from two ends to the center.

\subsection{Constant Thickness, Varying Width Design:}

In this design the thickness is kept constant over the entire length of the leaf spring while the width varies from a minimum at the two ends to a maximum at the center. 


\subsection{Constant Width, Varying Thickness Design:}

In this design the width is kept constant over the entire length of the leaf spring while the thickness varies from a minimum at the two ends to a maximum at the In this design both thickness and width are varied through out the leaf spring such that the cross-section area remains constant along the length of the leaf spring. Out of the above mentioned design concepts. The constant cross-section design method is selected due to thefollowingreasons: center.

\subsection{Constant Cross-Selection Design:}

Due to its capability for mass production and accommodation of continuous reinforcement of fibers. Since the cross-section area is constant through out the leaf spring, same quantity of reinforcement fiber and resin can be fed continuously during manufacture. Also this is quite suitable for filament winding process.

\section{SPECIFICATION OF EXISTING LEAF SPRING:}

\begin{tabular}{|c|l|c|}
\hline \multicolumn{2}{|c|}{ Specifications } \\
\hline 1 & Total Length of the spring (Eye to Eye) & $1540 \mathrm{~mm}$ \\
\hline 2 & Free Camber (At no load condition) & 01 \\
\hline 3 & No. of full length leave (Master Leaf) & $13 \mathrm{~mm}$ \\
\hline 4 & Thickness of leaf & $70 \mathrm{~mm}$ \\
\hline 5 & Width of leaf spring & $3850 \mathrm{~N}$ \\
\hline 6 & Maximum Load given on spring & $22426.09 \mathrm{~N} / \mathrm{mm}^{2}$ \\
\hline 7 & Young's Modulus of the spring & $23 \mathrm{~kg}$ \\
\hline 8 & Weight of the leaf spring & \\
\hline
\end{tabular}

\section{MATERIAL PROPERTIES OF E-GLASS/EPOXY:}

\begin{tabular}{|c|l|c|}
\hline Sl.No & \multicolumn{1}{|c|}{ Properties } & Value \\
\hline 1 & Tensile modulus along X-direction (Ex), MPa & 34000 \\
\hline 2 & Tensile modulus along Y-direction (Ey), MPa & 6530 \\
\hline 3 & Tensile modulus along Z-direction (Ez), MPa & 6530 \\
\hline 4 & Tensile strength of the material, Mpa & 900 \\
\hline 5 & Compressive strength of the material, Mpa & 450 \\
\hline 6 & Shear modulus along XY-direction (Gxy), Mpa & 2433 \\
\hline 7 & Shear modulus along YZ-direction (Gyz), Mpa & 1698 \\
\hline 8 & Shear modulus along ZX-direction (Gzx), Mpa & 2433 \\
\hline 9 & Poisson ratio along XY-direction (Nuxy) & 0.217 \\
\hline 10 & Poisson ratio along YZ-direction (NUyz) & 0.366 \\
\hline 11 & Poisson ratio along ZX-direction (NUzx) & 0.217 \\
\hline 12 & Mass density of the material ( $\square$ ), kg/mm3 & $2.6 \times 10^{-6}$ \\
\hline 13 & Flexural modulus of the material, MPa & 40000 \\
\hline 14 & Flexural strength of the material, MPa & 1200 \\
\hline
\end{tabular}




\section{THREE-DIMENSIONAL FINITE ELEMENT} ANALYSIS:

To design composite leaf spring, a stress analysis was performed using the finite element method done using ANSYS software. Modeling was done for every leaf with eight-node 3D brick element (solid 45) and five-node 3Dcontact element (contact 49) used to represent contact and sliding between adjacent surfaces of leaves. Also, analysis carried out for composite leaf spring with bonded end joints for Glass/Epoxy. The maximum and shear stresses along the adhesive layer were measured; represent FEA results for composite leaf spring (Glass/Epoxy). The maximum and shear stresses along the bonded adhesive layer for glass/epoxy were measured and plotted as shown in Figs 3 \& 4.

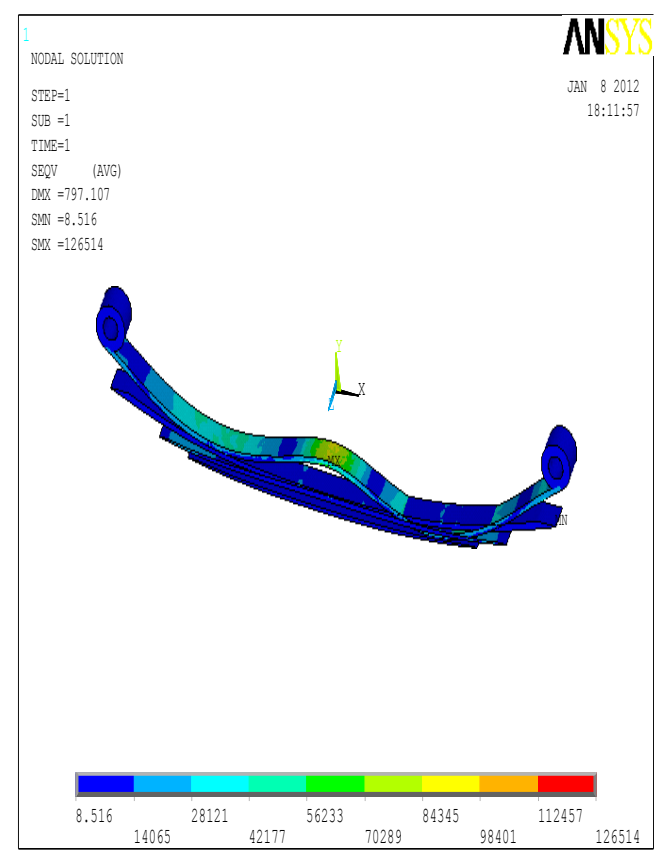

Fig. No: 4

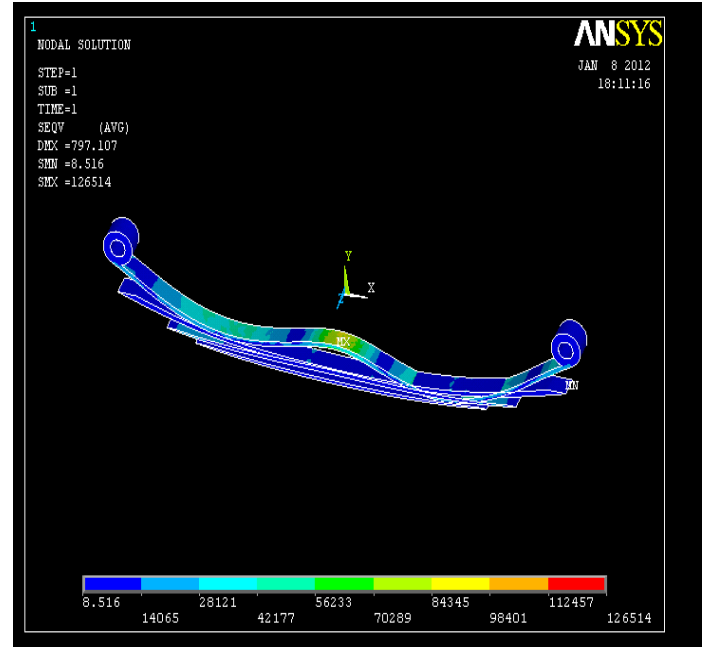

Fig. No: 3

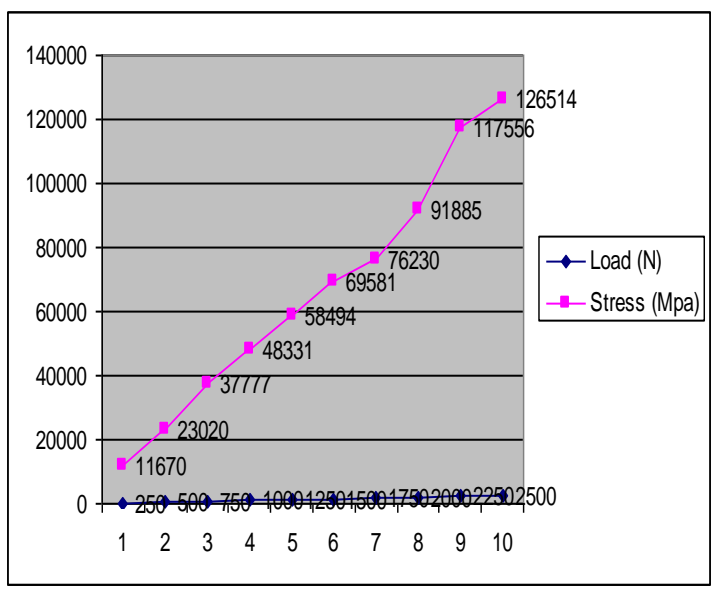

Fig. No: 5 - Stress distribution in adhesive for Glass/Epoxy Leaf spring. 


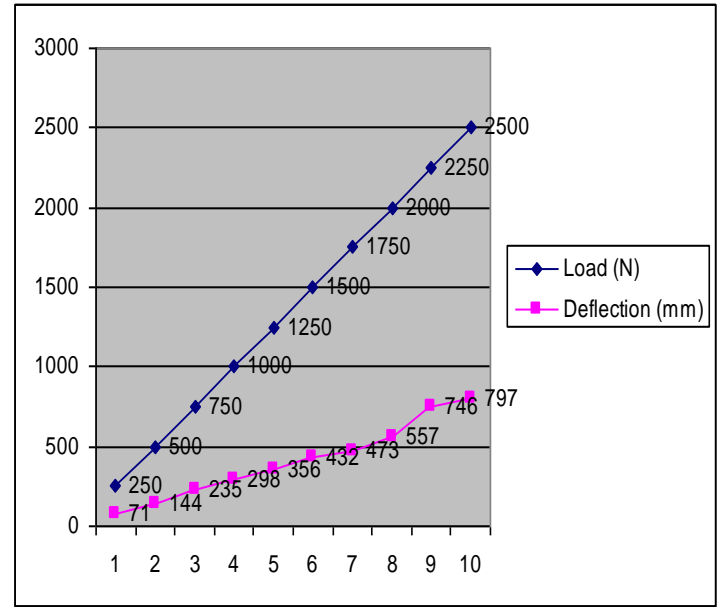

Fig. No: 6 - Deflection distribution in adhesive for Glass/Epoxy Leaf spring.

\section{CONCLUSION:}

The development of a composite leaf spring having constant cross sectional area, where the stress level at any station in the leaf spring is considered constant due to the parabolic type of the thickness of the spring, has proved to be very effective.

The study demonstrated that composites can be used for leaf springs for light weight vehicles and meet the requirements, together with substantial weight savings.

A comparative study has been made between composite and steel leaf spring with respect to weight, cost and strength. The 3-D modeling of composite leaf spring is done and analyzed using ANSYS.

From the results, it is observed that the composite leaf spring is lighter and more economical than the conventional steel spring with similar design specifications.

\section{REFERENCES:}

\subsection{Journal Papers:}

[1] Hawang, W., Han, K. S. Fatigue of Composites Fatigue Modulus Concept and Life Prediction Journal of Composite Materials, 1986.

[2] Dharam, C. K. Composite Materials Design and Processes for Automotive Applications. The ASME Winter Annual Meeting, San Francisco, 1978.

[3] Springer, George S., Kollar, Laszloa P. Mechanics of Composite Structures. Cambridge University Press, New York, 2003.

[4] AL-Qureshi, H. A. Automobile leaf springs from composite materials, Journal of Processing Technol., 2001 .

\subsection{Books:}

[5] P. Beardmore, Composite structure for automobiles, 1986.

[6] R.S. Khurmi, J.K. Kupta. A text book of Machine Design, 2000.

[7] R. M. Jones, Mechanics of Composite Materials. 2e, McGraw-Hill Book Company, 1990.

[8] K. Tanabe, T. Seino, Y. Kajio, Characteristics of Carbon/Glass Fiber Reinforced Plastic Leaf Spring, 1982.

\subsection{Chapters in Books:}

[9] R.S. Khurmi, J.K. Kupta. A text book of Machine Design, 2000, Chapter. 23, Page. No (866-874).

\subsection{Proceedings Papers:}

[10] Daugherty, R. L. Composite Leaf Springs in Heavy Truck Applications. K. Kawata, T.Akasaka (Eds). Composite Materials Proceedings of Japan-US Conference Tokyo, 1981. 